\title{
Con pluma de ganso revolucionario: Entrevista a Abelardo Estorino
}

\section{David Lisenby}

Sus piezas están recorridas por ese sentimiento, por esa necesidad de hacer algo, de alcanzar lo que falta. Sus personajes viven de lo que carecen, lo provocan, lo esperan, jadean por lograrlo. Es por eso que lentamente, y de un modo implacable, se van descubriendo cómo realmente son.

-Antón Arrufat, La manzana y la flecha

Abelardo Estorino es uno de los dramaturgos cubanos más prolíficos, más representados y más queridos como artista y como persona. Oriundo de Unión de Reyes, Matanzas, y residente en La Habana desde 1946, la producción teatral del incansable Estorino se extiende desde las vísperas de la Revolución del 59 hasta su reciente fallecimiento el 22 de noviembre de 2013. Premio Nacional de Literatura 1992 y Premio Nacional de Teatro 2002, su Teatro Completo (2012) de la Editorial Alarcos reúne en un tomo todas sus obras a excepción de la más reciente, Ecos y murmullos en Comala: Abelardo Estorino lee a Juan Rulfo (2012), la cual dramatiza la novela mexicana Pedro Páramo que tanto ha influido en su dramaturgia. Me senté a hablar con el humilde y generoso Estorino en su casa de la calle 25 en Vedado, $\mathrm{La}$ Habana, el 4 de julio de 2013. A continuación aparece una versión editada de nuestra conversación.

Desde la inclusión de El robo del cochino en la antología Teatro cubano: cuatro obras de 1961, el consenso crítico ha sido que esa pieza y otras como La casa vieja (1964) ejemplifican el teatro revolucionario temprano. ¿Cuál era tu opinión ante tal consideración en aquel momento y qué opinas ahora? 
Bueno, yo creo que yo abracé la Revolución con todo mi poder, ¿no? Con la pasión con que los cubanos estábamos hastiados del régimen anterior recibimos la Revolución y las obras tratan de tomar ese pensamiento, esa sensación, y dar la versión que tenemos de lo que está sucediendo. Y creo que las mías dan una imagen voluble o una imagen que tiene distintas aristas... porque ahora se ha hecho la película Casa vieja (2010) y es una versión completamente diferente.

Adria Santana protagoniza la matriarca en el filme. Yyo sé que tú tenías una relación profesional íntima con ella, ¿no? ¿Cómo han sido otras relaciones entre tú y los actores que han encarnado personajes tuyos?

Bueno, yo considero que yo tengo buen carácter. $Y$ trato de llevarme bien con los actores del reparto. Lo que pasa es que con Adria eso salió del trabajo y se convirtió en una amistad mucho más grande. En una amistad íntima. En una amistad íntima no sólo en el trabajo sino en la vida. Pero en el trabajo ella me ayudó mucho cuando ella hacía un personaje en una de mis obras. En casi todas mis obras que tenían más de un personaje femenino, pues ella siempre estuvo.

¿Y escribiste los papeles, los roles, pensando en ella?

No, no. Nunca. Pero después, algunas cosas se modificaron cuando ella las hacía y ella me señalaba algún dato que se podría arreglar y ahí ya era más fácil.

¿El monólogo Medea sueña Corinto (2008) tampoco fue escrito pensando en ella?

Mira, no fue escrito pensando directamente en ella. Pero ella siempre, a partir de nuestra relación de trabajo... siempre los personajes estuvieron pensando en ella como artista, lo que no quiere decir que yo modificara la visión que yo tenía de los personajes.

En tu obra más reciente, Ecos y murmullos en Comala (2012), y en la novela de Juan Rulfo en que está basada, algo que llama la atención es la idea de lo fantasmagórico y la presencia del pasado. Y en tus obras que están ambientadas en el siglo 19 - La dolorosa historia del amor secreto de don José Jacinto Milanés (1973), Vagos rumores (1992) y Parece blanca (1994) — hay una diferencia en cuanto al tratamiento del pasado en comparación a las obras anteriores $\mathrm{El}$ robo del cochino $y$ La casa vieja. 
Sí. Tendría que ponerme a analizar esa cosa. Porque utilizando ese punto exactamente, y ahora que tú dices, recuerdo que la madre de El robo del cochino va con frecuencia al cementerio por su hija perdida y eso se podría considerar rulfiano.

Entonces lo fantasmagórico en ese sentido...

Sí, lo asumí como parte propia cuando leí a Rulfo y me enamoré de esa obra.

Abel González Melo afirma, "La dolorosa historia... impulsó la visitación, por parte de muchos dramaturgos, de figuras de la literatura y el arte cubanos del siglo 19. El caso más notable, que continúa la brecha abierta en cuanto a concepción y forma por Estorino, es La verdadera culpa de Juan Clemente Zenea, de Abilio Estévez, para muchos su creación más lograda." Fuiste tú el director de la primera puesta en escena de La verdadera culpa... en 1986. Luego recurriste al siglo 19 en los años noventa con Vagos rumores y Parece blanca. ¿Qué se puede decir de esta trayectoria de emplear el siglo 19 en diferentes momentos contemporáneos de Cuba?

Yo creo que si, digamos, si en Vagos rumores hubiera temas que fueran... vamos a decir una palabra clara... peligrosos desde el punto de vista sociopolítico, para mí sería mejor usar un alter-ego y decía lo mismo, y no lo estaba diciendo sobre el presente. Yo no sé si ésa fue mi intención porque mi intención con Vagos rumores era reducir el tamaño de la obra [ $\mathrm{La}$ dolorosa historia...] de modo que fuera más fácil su puesta en escena. Pero sí que esa manera de ocultar la verdadera motivación está en esas obras que uno cita como en el siglo 19. Y yo creo que, de todas maneras, alcanzan una belleza artística al cambiarse de... que uno puede usar un lenguaje mucho más poético que con una obra que trata la realidad actual.

¿Qué puedes decir sobre el proceso de reescribir La dolorosa historia... en Vagos rumores? ¿Cómo influyeron las dificultades de montar La dolorosa historia... en la decisión de hacer la adaptación abreviada? ${ }^{2}$

La primera versión larga tenía como cincuenta personajes. Eso nadie lo iba a montar en la vida. Bueno, lo montó Roberto Blanco muy mal. El pobre, está muerto. Pero mira, él tenía una idea del teatro como, como de lujo... Hay un baile y la gente está vestida y baila bajo un candelabro y cosas así. Debe haber sido impresionante, pero la gente se puso una vez y ya, excepto una vez en Matanzas. Y la crítica lo vio muy mal. Vicente Re- 
vuelta hizo improvisaciones muy bonitas [en 1973]. Usó el patio de la Casa de Línea. Y para la muerte de Plácido, había unas manchas rojas sobre una pared como si fuera la pared donde lo fusilaron. Y, bueno, el patio se usaba para los esclavos. Era muy bonito aquello allí. Era para verlo hecho allí. Él dio tantos ensayos y Raquel [Revuelta] invitó a tanta gente a los ensayos que después ya no había interés. El teatro lo estaban reparando y cuando se terminó la reparación y Raquel dijo que era tiempo de montarlo, él no pudo hacer el cambio de un espacio abierto a un escenario a la italiana. Y entonces ella montó Algo muy serio, una obra de Héctor Quintero que estuvo meses y meses y meses, y ya después Vicente nunca volvió a montar La dolorosa historia. Y después yo hice Vagos rumores. Vagos rumores era la economía misma, tres actores.

Me interesa mucho el legado de Domingo del Monte. Se ha representado como abolicionista pero también como avaro, como oportunista, como hipócrita. ¿Cómo ves tú el Domingo del Monte de Vagos rumores?

Bueno, lo que pasa es que durante la Conspiración de La Escalera, se fue y dejó a los cubanos que estaban aquí solos. No les prestó ayuda. Yo tuve problemas con esa escena porque una mujer que tenía mucha importancia en el Partido Comunista, Mirta Aguirre, tachó esa escena y dijo que no había que hablar mal de Domingo del Monte, que Martí había dicho que era el más útil de los cubanos y eso. Por lo tanto, si Martí lo había dicho, ya no se podía analizar a Domingo del Monte. Porque yo creo que él era un hombre de la alta burguesía matancera que pudo haber luchado contra la esclavitud, pero hasta un punto. Hasta un punto. Pero ella era una mujer muy difícil porque yo hice una adaptación de Las impuras (1962) y hay una escena de lesbianismo. Y entonces ella tachó esa escena de lesbianismo y me dijo, “iNo!” Era en un libreto que yo le había dado para que ella lo leyera porque ella dirigía el departamento de teatro.

¿Qué significan para ti los Premios Nacionales de Literatura y de Teatro?

Que me respetan más. [Sonrie] Sí, yo creo que sí, ¿no? Y es una gran alegría.

¿Para qué público has escrito?

Para un público pequeño burgués culto. [Se ríe] Que va al teatro. Yo no sé, ¿eh? 
¿Hay proyectos que quisieras realizar que no han sido posibles hasta ahora? no se dará.

Estoy tratando de escribir una novela y eso, pero no sé si se dará o

¿De qué se trata?

Es como un personaje trágico que regresa para vengar un crimen. Soy como yo en mi juventud que regreso a mi pueblo para ver quién asesinó a mi padre. La novela puede tener, como toda obra actual, puede tener acentos de la lectura que uno ha hecho en su vida. Pero en este caso, es muy lejano en mi mente, ¿no? Es mi pueblo... cómo era yo cuando tenía 18 años o cuando tenía 25 y cómo encontraba el pueblo. Es como el personaje de La casa vieja, ¿no? Parece que siempre repito lo mismo, que estoy muy pobre de ideas.

En sus memorias (Yo, Publio, 2008), Raúl [Martínez] expresa mucho orgullo por tu carrera teatral. Y también habla de que los dos realizaron una gran parte de sus respectivas obras en esta misma casa de la Calle 25. ¿Cómo fue la influencia de él en tu producción teatral?

Yo creo que él... nunca había pensado en eso, ¿tú sabes? O tal vez lo había pensado pero no había tenido que decirlo. Yo creo que él influyó en que yo viera el arte como algo muy importante en mi vida. Así que dedicarse a eso, no que yo siga siendo un dentista, sino que encontraba algo que me ayudaba a soportar la vida y a hacer que, por ejemplo, el homosexualismo no fuera algo de lo cual yo me sintiera dolido al sentir que había amor en eso y que no era lo que la gente común opina, ¿no? Porque él además se abrió completamente. También eso yo creo que sucedió por su viaje a Chicago. Porque ver el mundo de una perspectiva más amplia te permite decir una cosa de ti mismo.

Si tuvieras una bola de cristal, ¿qué dirías sobre el futuro de la dramaturgia cubana para los próximos años?

Yo creo que tiene un momento de brillantez. Me parece que sí que ya están utilizando más la fantasía, dejando el realismo vano y seco, y que encontraron un mundo más poético.

Y ese cambio es la trayectoria que han tomado tus obras durante tu carrera.

Sí, yo creo que sí. Porque yo empecé escribiendo obras de un realismo muy chato, ¿no? Aunque yo creo que siempre cuidé mi lenguaje para que tuviera cierta poesía. A veces la gente piensa que hablar en cubano es hablar 
con "vete pa' allá" y "ven pa' acá" y eso, y yo creo que no. Que sí eso está en el ritmo del lenguaje.

Entonces, ¿hay alguna poesía especificamente cubana en el lenguaje de tus obras?

Ya, yo no sé si la vas a encontrar. Tú me avisas, ¿sí? [Risas]

¿Y la novela tendría también esa poesía?

Ya pero es un juego de niños. Es que tendría que irme a una casa de campo, así como en el siglo 19, ¿no? Y entonces escribir con pluma de ganso.

University at Albany, SUNY

\section{Notas}

1 De Cada vez que te digo lo que siento: Cercanías con Abelardo Estorino. Cienfuegos: Reina del Mar Editores, 2005. 32-33.

2 Esta y la siguiente pregunta, así como las respuestas de Estorino, provienen de una conversación previa que tuvimos en el mismo lugar el 3 de enero de 2011. 